\title{
Efficacy of Skin, Connective Tissue, Aponeurosis Galea, Loose Areolar Tissue, and Pericranium Acupuncture Techniques in Stroke Patients in Improving Muscle Strength of Motion Limbs
}

\author{
Indri Seta Septadina*, Erial Bahar \\ Department of Anatomy, Faculty of Medicine, Universitas Sriwijaya, Palembang, Indonesia
}

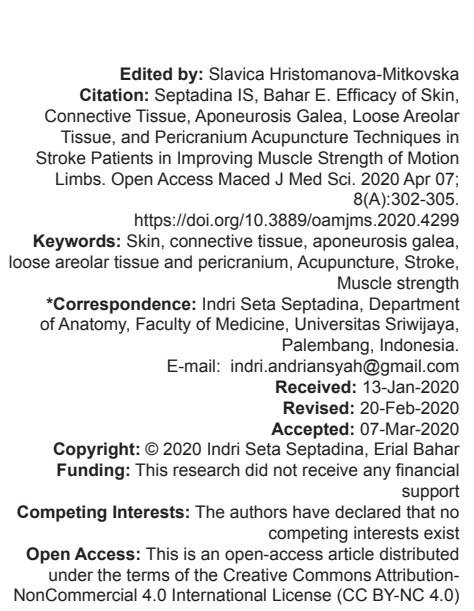

\section{Introduction}

Stroke is a clinical condition because of the disruption of blood flow to the brain, either by obstruction of blood vessels or rupture of blood vessels of the brain. Stroke is a cause of death. In the United States, it is estimated that every year 795,000 people suffered from stroke attack, about $15.7 \%$ or 125,000 people died, and the rest were getting weaker or more severe limbs. Based on these data, more than 650,000 stroke survivors needed further therapy and treatment related to mild or severe relief caused by stroke. The data will not be much different from what happened in the world. Defects that cause stroke lesions require more serious and longer handling and will be very burdensome for patients and health insurance. Not only does this disability require a large health fund for treatment but also it will cause an economic downturn from patients who increase disability. Of course, it needs to be developed more seriously and is being used and developing methods of limb disability in stroke patients [1], [2], [3], [4].

The method of needle sticking in the head skin, connective tissue, aponeurosis galea, loose areolar tissue, and pericranium (SCALP) is in accordance with the area in the cerebral cortex that is related to the function of the cerebral cortex known as Zhu's scalp acupuncture. Needling at this location is done because there is a complicated system of connections called acupoints (acupuncture points) that related to various bodily functions and organs. Motoric cortex is located in the anterior part of the central gyrus in the brain. Stimulation on this point can open blood vessels and provides better blood flow. Moreover stimulation with acupuncture is also useful to facilitate repairment of 
segmental system, stimulate spinal cord, regenerate peripheral nerves, maintain the rest alive central nerves, that is characterized by the improvement of muscle strength [5], [6], [7], [8].

The needle sticking technique in SCALP can increase blood flow and energy in the cerebral motor cortex of the brain. Cerebral cortex stimulation in the brain can also activate nerve impulse signals toward to the extremities so as to increase muscle strength [9], [10]. However, study related rehabilitation effort for stroke survivor by needling on the SCALP to stimulate cerebrum motor cortex in Palembang, Indonesia, has not been done yet. This research aimed to prove the effectivity of needle sticking on SCALP to strengthen limb muscle in stroke patients.

\section{Materials and Methods}

The research design used in this study was a quasi-experimental, pre-test-post-test without control group. This study was took place at the Holistic Medical Center Complementary Clinic in Palembang. The subjects of this study were post stroke recovery patients who met the inclusion and exclusion criteria. The inclusion criteria of this study were stroke patients who were in the recovery phase (after the critical period had passed) and stroke patients who had an attack $<1$ year. The measured variable was the strength of the limbs after stimulation of the cerebral cortex at the point of the motor cortex by the subcutaneous pricking method. The sampling method of this study was consecutive sampling, namely, recovery post-stroke patients who were hospitalized or outpatient of all over hospitals in Palembang, Indonesia.

In this study, needle pricking was performed in the cerebral motor cortex which is located in the anterior central sulcus. Stimulation is done 10 times for 2 weeks. Stimulation was aimed to activate and increase blood flow to the cerebral cortex in cerebrum. In this study, an assessment of muscle strength in the upper and lower limbs was performed using manual muscle testing (MMT) measurement before and after therapy. Analysis of muscle strength before and after cerebral cortex stimulation through needle pricking on the SCALP of the head was analyzed by t-test dependent using SPSS 18 for windows. Data were displayed in tabular form, with a significance of $p<0.05$.

\section{Results}

The subjects of this study were eight people consisting of four men (50\%) and four female patients $(50 \%)$ who had passed the critical stroke and were in the recovery phase within a period of recovery $<1$ year after stroke attack, because the golden healing phase which is the best for recovering the strength of motion after a stroke is $<6$ months and a maximum of 1 year. The age of the study subjects was between 45 and 75 years old because of epidemiological reason that stroke generally occurred at the age over 45 years [4]. The study subjects were all non-hemorrhagic stroke patients or strokes caused by obstruction in the blood vessels of the brain to homogenize the research subjects to avoid research bias.

Overall in Table 1, it can be seen that the frequency of the number of subjects who experienced improvement in joint motion of each joint was much greater than the frequency of the number of subjects who had no improvement. About $90 \%$ of the study subjects felt improvement in joint motion of each joint.

Table 2 shows the efficacy of the treatment for improvement in muscle strength in each joint and

Table 1: Frequency of improvement in muscle strength in joint motion

\begin{tabular}{|c|c|c|c|c|c|c|}
\hline \multirow[t]{3}{*}{ Joint Movement } & \multicolumn{6}{|c|}{ Muscle strength improvement } \\
\hline & \multicolumn{2}{|c|}{ No improvement } & \multicolumn{2}{|l|}{ Mild (<2) } & \multicolumn{2}{|c|}{ Moderate (2-3) } \\
\hline & Total patient & $\%$ & Total patient & $\%$ & Total patient & $\%$ \\
\hline \multicolumn{7}{|c|}{ Shoulder joint movement } \\
\hline Abduction & 1 & 12.5 & 4 & 50 & 3 & 37.5 \\
\hline Adduction & 1 & 12.5 & 4 & 50 & 3 & 37.5 \\
\hline Flexion & 1 & 12.5 & 4 & 50 & 3 & 37.5 \\
\hline Extension & 1 & 12.5 & 4 & 50 & 3 & 37.5 \\
\hline \multicolumn{7}{|c|}{ Elbow joint movement } \\
\hline Flexion & 1 & 12.5 & 5 & 62.5 & 2 & 25 \\
\hline Extension & 1 & 12.5 & 6 & 75 & 1 & 12.5 \\
\hline \multicolumn{7}{|c|}{ Wrist joint movement } \\
\hline Flexion & 1 & 12.5 & 1 & 12.5 & 5 & 62.5 \\
\hline Extension & 1 & 12.5 & 1 & 12.5 & 5 & 62.5 \\
\hline \multicolumn{7}{|l|}{ Hip joint movement } \\
\hline Bridging & 0 & 0 & 5 & 62.5 & 3 & 37.5 \\
\hline Abduction & 1 & 12.5 & 3 & 37.5 & 4 & 50 \\
\hline Adduction & 1 & 12.5 & 3 & 37.5 & 4 & 50 \\
\hline Flexion & 1 & 12.5 & 3 & 37.5 & 4 & 50 \\
\hline Extension & 1 & 12.5 & 4 & 50 & 3 & 37.5 \\
\hline \multicolumn{7}{|c|}{ Knee joint movement } \\
\hline Flexion & 1 & 12.5 & 4 & 50 & 3 & 37.5 \\
\hline Extension & 1 & 12.5 & 4 & 50 & 3 & 37.5 \\
\hline \multicolumn{7}{|c|}{ Ankle joint movement } \\
\hline Dorsal flexion & 0 & 0 & 3 & 37.5 & 5 & 62.5 \\
\hline Plantar flexion & 0 & 0 & 4 & 50 & 4 & 50 \\
\hline
\end{tabular}


Table 2: Strength score of joint limbs

\begin{tabular}{|c|c|c|c|}
\hline Joint type & Motion & Mean \pm SD Muscle strength & $p$-value ${ }^{*}$ \\
\hline \multirow{8}{*}{ Shoulder joint } & Abduction T1 & $2.25 \pm 1.16$ & 0.015 \\
\hline & Adduction T10 & $3.50 \pm 1.51$ & \\
\hline & Adduction T1 & $2.25 \pm 1.16$ & 0.015 \\
\hline & Adduction T10 & $3.50 \pm 1.51$ & \\
\hline & Flexion T1 & $2.25 \pm 1.16$ & 0.015 \\
\hline & Flexion T10 & $3.50 \pm 1.51$ & \\
\hline & Extension T1 & $2.12 \pm 1.12$ & 0.016 \\
\hline & Extension $\mathrm{T} 10$ & $3.43 \pm 1.54$ & \\
\hline \multirow[t]{4}{*}{ Elbow Joint } & Flexion T1 & $2.50 \pm 1.30$ & 0.016 \\
\hline & Flexion T10 & $3.93 \pm 1.65$ & \\
\hline & Extension T1 & $2.50 \pm 1.30$ & 0.016 \\
\hline & Extension $\mathrm{T} 10$ & $3.75 \pm 1.62$ & \\
\hline \multirow[t]{4}{*}{ Wrist Joint } & Flexion T1 & $1.25 \pm 1.58$ & 0.016 \\
\hline & Flexion T10 & $3.43 \pm 1.45$ & \\
\hline & Extension T1 & $1.25 \pm 1.58$ & 0.016 \\
\hline & Extension T10 & $3.43 \pm 1.45$ & \\
\hline \multirow[t]{10}{*}{ Sendi pinggul } & Bridging T1 & $2.75 \pm 0.88$ & 0.010 \\
\hline & Bridging T10 & $4.37 \pm 1.06$ & \\
\hline & Abduction T1 & $2.37 \pm 1.30$ & 0.016 \\
\hline & Abduction T10 & $4.00 \pm 1.77$ & \\
\hline & Abduction T1 & $2.37 \pm 1.30$ & 0.016 \\
\hline & Abduction T10 & $4.00 \pm 1.77$ & \\
\hline & Flexion T1 & $2.37 \pm 1.30$ & 0.016 \\
\hline & Flexion T10 & $4.00 \pm 1.77$ & \\
\hline & Extension T1 & $2.37 \pm 1.30$ & 0.016 \\
\hline & Extension $\mathrm{T} 10$ & $4.00 \pm 1.77$ & \\
\hline \multirow[t]{4}{*}{ Knee Joint } & Flexion T1 & $2.62 \pm 1.18$ & 0.016 \\
\hline & Flexion T10 & $4.00 \pm 1.69$ & \\
\hline & Extension T1 & $2.50 \pm 1.19$ & 0.016 \\
\hline & Extension T10 & $3.87 \pm 1.72$ & \\
\hline \multirow[t]{4}{*}{ Ankle Joint } & Dorsoflexion T1 & $2.00 \pm 1.19$ & 0.009 \\
\hline & Dorsoflexion T10 & $3.62 \pm 1.30$ & \\
\hline & Plantarflexion T1 & $2.25 \pm 1.16$ & 0.010 \\
\hline & Plantarflexion T110 & $3.75 \pm 1.28$ & \\
\hline
\end{tabular}

is statistically significant, $p<0.05$. The improvement in muscle strength score almost doubled after being treated with SCALP acupuncture.

\section{Discussion}

Based on classical acupuncture theory, the meridian pathway is an important flow system in the human body. This pathway will form certain circuits that can determine the disturbance in the body as well as being a clue in determining the point of therapy. This meridian pathway functions link between internal organs and structures that exist in the peripheral such as in the trunk and limbs through the spinal cord and these end in the brain (cerebrum). Based on the principles of Eastern Medicine, to run the meridian system optimally it takes energy to move the functions of the organs that be regulated by the meridians. Around human head, there is a "GV 20" located in the vertex. Stimulation on this point was believed to be able to move energy to the central nervous system in the brain [11], [12], [13], [14], [15].

Other studies have shown that giving stimulation to cerebral motor cortex projections in the motor area can accelerate nerve stimulation to the associated peripheral system. Several point locations are also needed to support rehabilitation therapy in stroke patients. Stroke management using the Bobath method and physical exercise in stroke patients is proven to increase muscle strength in stroke patients better. Although there were some studies declared that acupuncture therapy had no improvement in stroke patients, this study found improvements in muscle strength through MMT assessments in eight stroke patients [15], [16], [17], [18], [19], [20].

\section{Conclusion}

SCALP acupuncture technique was effective in improving muscle strength of motion limbs on stroke patients.

\section{Acknowledgment}

The authors would like to express their sincere gratitude to the Clinical Research Unit of Faculty of Medicine, Universitas Sriwijaya, Palembang, Indonesia.

\section{References}

1. Lozano R, Naghavi M, Foreman K, Lim S, Shibuya S, Aboyans V, et al. Global and regional mortality from 235 causes of death for 20 age groups in 1990 and 2010: A systematic analysis for the global burden of disease study 2010. Lancet. 2012;380(9859):2095-128.

PMid:23245604

2. Murray CJ, Vos T, Lozano R, Naghavi M, Flaxman $A D$, Michaud C, et al. Disability-adjusted life-years (DALYs) for 291 diseases and injuries in 21 regions, 1990-2010: A systematic analysis for the Global Burden of Disease Study 2010. Lancet. 2012;380(9859):2197-223.

PMid:23245608

3. Feigin VL, Forouzanfar MH, Krishnamurthi R, Mensah GA, Connor M, Bennett DA, et al. Global and regional burden of stroke during 1990-2010: Findings from the global burden of disease study 2010. Lancet. 2014;383(9913):245-54. PMid:24449944

4. Roger VL, Go AS, Lloyd-Jones DM, Adams RJ, Berry JD, Brown TM, et al. Heart disease and stroke statistics 2011 update: A report from the American heart association. Circulation. 2011;123(4):e18-209. PMid:21160056

5. He J, Gu D, Wu X, Reynolds K, Duan X, Yao C, et al. Major causes of death among men and women in China. N Engl $J$ Med. 2005;353(11):1124-34.

PMid:16162883

6. Zhao D, Liu J, Wang W, Zeng Z, Cheng J, Sun J, et al Epidemiological transition of stroke in China: Twenty-one-year observational study from the Sino-MONICA-Beijing project. Stroke. 2008;39(6):1668-74

PMid: 18309149 
7. Liu M, Wu B, Wang WZ, Lee LM, Zhang SH, Kong LZ. Stroke in China: Epidemiology, prevention, and management strategies. Lancet Neurol. 2007;6(5):456-64.

PMid: 17434100

8. Jia Q, Liu LP, Wang YJ. Stroke in China. Clin Exp Pharmacol Physiol. 2010;37(2):259-64.

PMid:19769611

9. Liu L, Wang D, Wong KS, Wang Y. Stroke and stroke care in China: Huge burden, significant workload, and a national priority. Stroke. 2011;42(12):3651-4.

PMid:22052510

10. NICE. Stroke: Diagnosis and Initial Management of Acute Stroke and Transient Ischaemic Attack (TIA). National Institute for Health and Clinical Excellence: NICE Clinical Guideline. Vol. 68. London: Royal College of Physicians (UK); 2008. p. 1-16.

11. SIGN. Management of Patients with Stroke: Rehabilitation, Prevention and Management of Complications, and Discharge Planning. Vol. 118. Scottish Intercollegiate Guidelines Network; 2010. p. 1-14.

12. Gu J, Wang $Q$, Wang XG, Li H, Ming H, Dong X, et al. Assessment of registration information on methodological design of acupuncture RCTs: A review of 453 registration records retrieved from $\mathrm{WHO}$ international clinical trials registry platform. Evid Based Complement Alternat Med. 2014;2014(8):614850.

13. Bai L, Tian J, Zhong C, Xue T, You Y, Chen P, et al. Acupuncture modulates temporal neural responses in wide brain networks: Evidence from fMRI study. Mol Pain. 2010;6(1):73.

PMid:21044291

14. Li L, Zhang H, Meng SQ, Qian HZ. An updated meta-analysis of the efficacy and safety of acupuncture treatment for cerebral infarction. PLoS One. 2014;9(12):e114057.

PMid:25438041

15. NIH Consensus Development Panel. NIH Consensus Conference. Acupuncture. JAMA. 1998;280(17):1518-24. PMid:9809733

16. World Health Organization. Acupuncture: Review and Analysis Reports on Controlled Clinical Trials. Geneva: World Health Organization; 2002.

17. Wang HQ, Wang F, Liu JH, Dong GR. Introduction on the schools of the scalp acupuncture for treatment of the stroke hemiplegia. Chinese Acupuncture \& Moxibustion. 2010;30(9):783-6.

18. $\mathrm{Xu} \mathrm{XH}$, Zheng $\mathrm{P}$, Wang $\mathrm{FC}$. The comparison and analysis of curative effect for three scalp acupuncture school. Jilin J Tradit Chin Med. 2007;4(27):47-8.

19. Jiao SF. Head Acupuncture. Beijing: Foreign Languages Press; 1993. p. 17-22.

20. Sze FK, Wong E, Kevin KH, Or KH, Lau J, Woo J. Does acupuncture improve motor recovery after stroke? A meta-analysis of randomized controlled trials. Stroke. 2002;33(11):2604-19.

PMid:12411650 